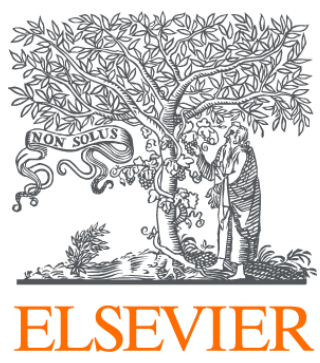

Since January 2020 Elsevier has created a COVID-19 resource centre with free information in English and Mandarin on the novel coronavirus COVID-

19. The COVID-19 resource centre is hosted on Elsevier Connect, the company's public news and information website.

Elsevier hereby grants permission to make all its COVID-19-related research that is available on the COVID-19 resource centre - including this research content - immediately available in PubMed Central and other publicly funded repositories, such as the WHO COVID database with rights for unrestricted research re-use and analyses in any form or by any means with acknowledgement of the original source. These permissions are granted for free by Elsevier for as long as the COVID-19 resource centre remains active. 


\section{(Mis-)understanding COVID-19 and digit ratio: Methodological and statistical issues in Manning and Fink (2020)}

In their study, Manning and Fink ([1]; henceforth M\&F); report positive associations between the relative lengths of the index and ring fingers (2D:4D)—an intended proxy for prenatal exposure to testosterone-and two national COVID-19 outcomes: case fatality rate (CFR) and the percentage of male deaths (\%MD). Whilst we encourage scientific practice that can aid international responses to COVID-19, there are significant methodological and analytic concerns with M\&F's paper that lead it to be uninformative in the current climate.

First, whilst M\&F assume that 2D:4D functions as a proxy of prenatal testosterone, it should be noted that scholars have repeatedly pointed to the lack of evidence for this relationship [2-4] and 2D:4D findings across different contexts have failed to replicate [5].

Second, M\&F set out to test the hypothesis that prenatal testosterone levels are associated with COVID-19 mortality risk. To test this, M\&F examine data on national average 2D:4D and national COVID-19 outcomes. These variables in this study are sampled from separate populations and do not give insight into the proposed individual level mechanism in M\&F's discussion. Crucially, associations that hold at one level of analysis (e.g., nations), do not necessarily hold at another level of analysis - here specifically at the individual level [6].

Third, in their use of national aggregates for analysis, the number of cases for analysis is far from the claimed 103,482 men and 83,366 women. Rather, most of their analyses are based on 41 cases, and in the central finding for \%MD, only 16 cases. Simulation studies show that such small samples yield highly volatile and unreliable correlation coefficients [7].

Even when casting aside these methodological issues, a closer look at the data reveals different results to M\&F's findings. National COVID19 data is continuously updated and provides an opportunity to test the robustness of M\&F's results. M\&F only examined data from one time point (which appears to be from April 8, and not April 21 as reported in the paper). Analyzing the most recent data from Global Health 50/50 (May 20), with a larger set of countries (31 instead of 16), we find no significant association between male 2D:4D and \%MD (left hand: $r=-0.32, p=.079$; right hand: $r=-0.20, p=.283$; see Fig. 1 ).

In sum, the reported study is ill-suited to test M\&F's hypothesis and there is little to learn about the role of testosterone in the current pandemic in this paper. Further, analyses of updated COVID-19 data question the reliability of M\&F's claims. There is an urgent need for high quality science during this pandemic, and any results that might inform medical decisions surrounding the COVID-19 pandemic should be subject to, and withstand, close scrutiny. We show that M\&F's results do not, and in fact their study cannot, advance our understanding of COVID-19 and its relationship to male or female health outcomes.

\section{Open practice statement}

The code and data used to create the analyses and figure in this comment are available from the Open Science Framework: osf.io/ p8k43. 

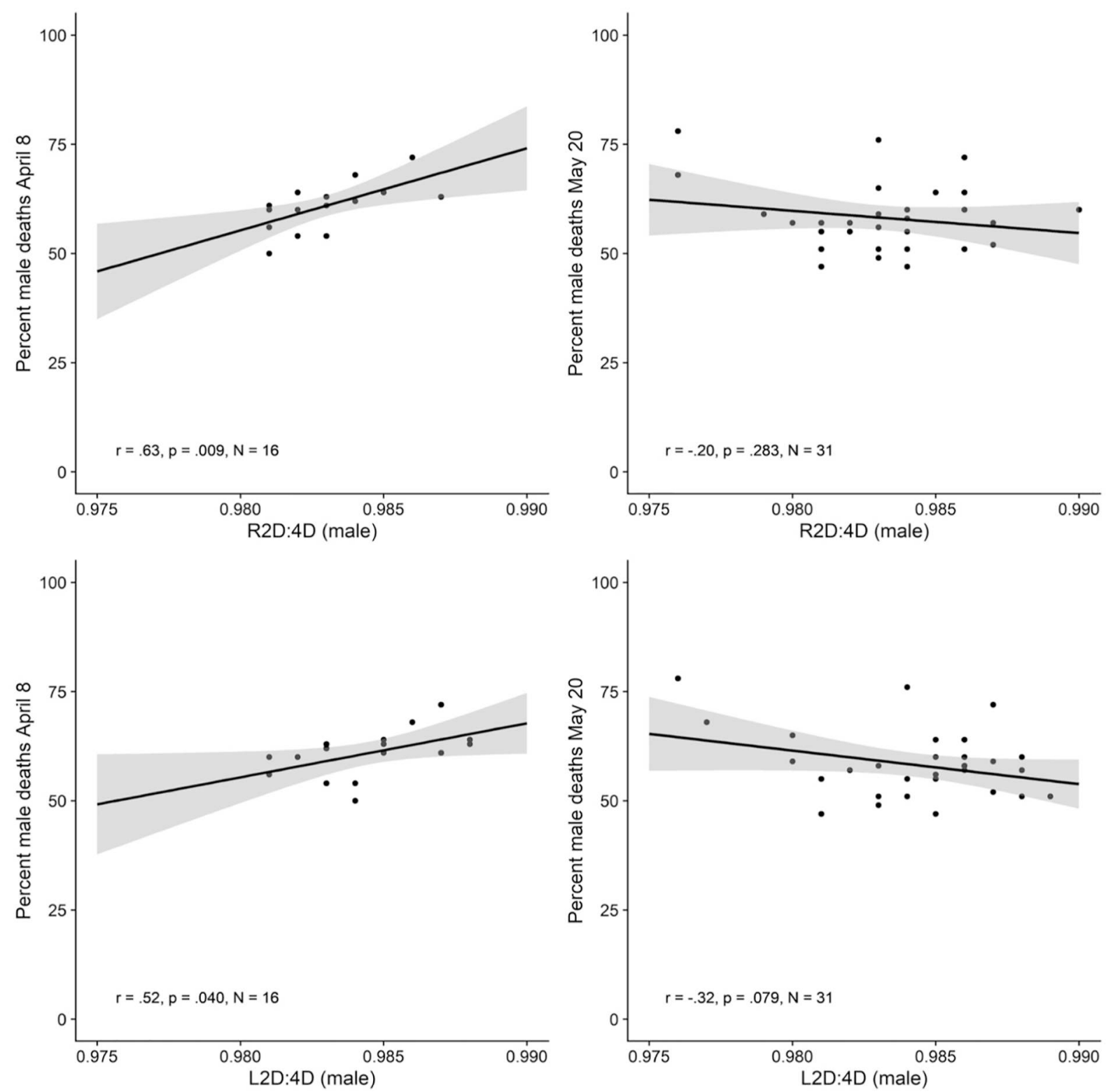

Fig. 1. Left column: Data from M\&F; male death percentage and 2D:4D, April 8th 2020. Right column: Male death percentage and 2D:4D, May 20th 2020.

\section{Declaration of competing interest}

None declared.

\section{References}

[1] J.T. Manning, B. Fink, Understanding COVID-19: digit ratio (2D:4D) and sex differences in national case fatality rates, Early Hum. Dev. 146 (2020) Jul 1. (105074).

[2] L.P. Hollier, J.A. Keelan, E.S.L. Jamnadass, M.T. Maybery, M. Hickey,

A.J.O. Whitehouse, Adult digit ratio (2D:4D) is not related to umbilical cord androgen or estrogen concentrations, their ratios or net bioactivity, Early Hum. Dev. 91 (2) (2015) 111-117 Feb 1.

[3] M. Voracek, M. Kossmeier, U.S. Tran, Which data to meta-analyze, and how? A specification-curve and multiverse-analysis approach to meta-analysis, Zeitschrift Für Psychologie 227 (1) (2019) 64-82, https://doi.org/10.1027/2151-2604/ a000357.

[4] W.I. Wong, M. Hines, Interpreting digit ratio (2D:4D)-behavior correlations: 2D:4D sex difference, stability, and behavioral correlates and their replicability in young children, Horm. Behav. 78 (2016) 86-94 Feb 1.

[5] J. Hilgard, C.R. Engelhardt, J.N. Rouder, I.L. Segert, B.D. Bartholow, Null effects of game violence, game difficulty, and 2D:4D digit ratio on aggressive behavior, Psychol. Sci. (2019 Mar 7), https://doi.org/10.1177/0956797619829688 Internet. [cited 2020 May 21]; Available from.

[6] W.S. Robinson, Ecological correlations and the behavior of individuals, American Sociological Review 15 (3) (1950) 351-357, https://doi.org/10.2307/2087176 Inte.

[7] F.D. Schönbrodt, M. Perugini, At what sample size do correlations stabilize? J. Res. Pers. 47 (5) (2013) 609-612 Oct 1.

Alex L. Jones ${ }^{\mathrm{a}, *}$, Liam P. Satchell ${ }^{\mathrm{b}}$, Bastian Jaeger ${ }^{\mathrm{c}}$, Christoph Schild ${ }^{\mathrm{d}}$ ${ }^{a}$ Department of Psychology, Swansea University, UK ${ }^{\mathrm{b}}$ Department of Psychology, University of Winchester, UK ${ }^{\mathrm{c}}$ Department of Social Psychology, Tilburg University, Netherlands ${ }^{\mathrm{d}}$ Department of Psychology, University of Siegen, Germany E-mail address: alex.1.jones@swansea.ac.uk (A.L. Jones).

\footnotetext{
${ }^{*}$ Corresponding author.
} 